\title{
Analysis of the Evolution of Income Disparities Among WAEMU Member Countries
}

\author{
Coulibaly Niénéyéri Mamadou ${ }^{1}$ \\ ${ }^{1}$ Department of Economics and Management, Jean Lorougnon Guédé University, Daloa, Côte d'Ivoire \\ Correspondence: Coulibaly Niénéyéri Mamadou, Department of Economics and Management, Jean Lorougnon \\ Guédé University, Daloa, Côte d'Ivoire. Tel: 225-050-558-4249/225-077-980-1340.
}

Received: December 1, 2021

Accepted: January 16, 2022

Online Published: January 18, 2022

doi:10.5539/ijef.v14n2p97

URL: https://doi.org/10.5539/ijef.v14n2p97

\begin{abstract}
The main aims of this study are to examine the income disparities' evolution among the West-African Economic and Monetary Union (WAEMU) countries over the period 1980-2019, and to determine whether the reforms implemented in the region since 1994 have helped to reduce or to accentuate the income disparities among the Member States of the Union. The approach used for the analysis is that of sigma-convergence. It consists in studying the evolution of income dispersion over time, standard deviation being generally used as measure of dispersion. The results obtained show a reduction of per capita income inequalities among the WAEMU Member States. They also point out that the reforms undertaken in the area since 1994 have partly helped to reduce the income disparities among nations. In view of these findings, the study recommends to the community authorities to continue the implementation of the reforms and to reinforce the coordination as well as the harmonization of economical, financial and commercial policies of the Union.
\end{abstract}

Keywords: income disparities, income inequalities, Sigma-Convergence and WAEMU

\section{Introduction}

The West African Economic and Monetary Union (WAEMU) is a sub-regional organisation comprising eight countries, namely Benin, Burkina, Ivory Coast, Guinea-Bissau, Mali, Niger, Senegal and Togo. Its main task is to create a harmonised and integrated economic area in which there is complete freedom of movement for people, capital, goods, services and factors of production, as well as rights of residence and establishment. The WAEMU countries, with the exception of Guinea-Bissau, have for a long time been in a monetary integration [West African Monetary Union (WAMU)]. As for the economic aspect of integration, it dates from 1994. The transformation of the monetary union into an economic and monetary union was followed by several reforms (implementation of the WAEMU treaties, reforms in the context of the devaluation of the CFA franc, etc.). Some of these reforms were intended to bring economies closer together. The Economic Commission for Africa (2007) notes that one of the objectives of regional integration is to facilitate the reduction of differences between countries in terms of the income (and therefore the welfare) of the population. This objective is all the more important because, as Niang (2010) points out, the African continent is characterised by economic inequalities between countries. Studies examining income disparities between countries have been inspired by the work of Barro and Sala-i-Martin (1990, 1991 and 1992) based on the neoclassical growth model. According to this model, poorer economies tend to grow faster than richer ones, so that income disparities eventually disappear or at least diminish.

Observation of the evolution of per capita income in WAEMU member states, however, reveals some ambiguities despite the economic integration process. Indeed, while income disparities between some countries seem to be narrowing, those between other states seem to be widening at the same time. For example, the income gap between Senegal and Benin narrowed by 72\% between 2010 and 2019 from \$407 PPP (Purchasing Power Parity) to \$113 PPP (See IMF World Economic Outlook (WEO) 2009, 2017, 2018 and 2020 data). At the same time, the income gap between Burkina and Niger has widened by 91\% from \$527 PPP in 2010 to \$1005 PPP in 2019. In these circumstances, can it be said that there is an increase in income disparities between WAEMU member states over time? Or on the contrary, to say that there is a reduction in income inequality between these countries? In the latter case, would the process of reducing income disparities have been helped by the reforms undertaken since 1994? Especially when the figures simultaneously show an upward trend in the real GDP 
growth rate in all the countries in question and an upward trend in the Human Development Index (HDI) in these same countries, in particular over the period covered by the reforms (see Appendix 12). In addition, the countries with the lowest initial HDI values have, on average, grown faster, thereby narrowing their gaps with other countries (Appendix 12).

The general objective of our study is to analyse the evolution of income disparities between WAEMU member states. Specifically, the aim is to verify whether there has been a reduction or rather a worsening of income inequalities among WAEMU member countries over the period 1980-2019 and to determine whether the reforms implemented within the Union since 1994 have contributed to reducing or increasing income disparities among states. To achieve these objectives, we formulate the following hypotheses: 1) Income inequalities between WAEMU member states are narrowing over time; 2) The reforms undertaken within the WAEMU from 1994 onwards have contributed to a reduction in disparities in per capita income between the economies of this zone.

The subject of this study is convergence. Convergence in economics is a phenomenon that results in a decrease over time in per capita income differences between two or more countries. This phenomenon is also known as real convergence. There is, moreover, another concept of convergence used in Community matters: nominal convergence. This concept refers to the trend towards greater uniformity of nominal variables indicative of macroeconomic stability (Gbetnkom, 2007). The present research deals with real convergence and the approach used is that of sigma-convergence since it allows us to consolidate and go beyond the limits of beta-convergence by explaining the temporal information included in the cross-sectional variance (Gannoun, 2007). Quah (1993) has, moreover, shown that the best way to assess the convergence hypothesis is to exploit the temporal information included in the cross-sectional variance (Guetat \& Serranito, 2009). Furthermore, according to the homogenisation principle, the most important convergence concept is probably that of sigma-convergence, which implies a reduction in the dispersion of the performance of different economies over time (Allaoui \& Chkir, 2006).

The interest of this topic lies on two levels. Firstly, at the political level, a reduction in income inequalities among countries is a source of stability for each of the Union member states. Secondly, at the community level, the conclusions of the study will make it possible to perceive the effects of the various reforms undertaken within the WAEMU since 1994.

Studies that have already addressed the issue of income disparity between WAEMU member states (Diop, 2002; Combey \& Mally, 2010; Gbohoui, 2013) have used either a Figureical analysis, a descriptive analysis, the non-parametric Wilcoxon test, or a combination of at least two of the above approaches. To be more precise, Diop (op. cit.) has carried out both a Figureical and a descriptive study. Combey and Mally (op. cit.) instead carried out a Figureical analysis which they supplemented with the non-parametric Wilcoxon test. In the case of Gbohoui (op. cit.), he carried out both a Figureical study, a descriptive analysis and the non-parametric Wilcoxon test.

This study goes beyond the approaches used by these three researchers to examine the problem of income disparity among WAEMU member countries by conducting econometric estimations (linear trend equation, quadratic trend model, kinked trend model). It also uses various other techniques (splitting the study period into two sub-periods, use of a dummy variable, Student comparison test, etc.) to determine the impact of the reforms implemented from 1994 onwards on the evolution of income inequalities between the WAEMU member countries.

The rest of the article is organised as follows. Section II reviews the literature, while the methodological approach is presented in Section III. Section IV presents and discusses the results of the study. Finally, conclusions are proposed in Section V.

\section{Review of the literature on the issue of income disparities among countries}

At the outset of this literature review, some theoretical aspects of inequality need to be addressed. In this respect, it is important to note that two concepts of income inequality are commonly used in economics: inequality between countries and inequality within countries. The study of the first concept refers, in a way, to the study of the phenomenon of convergence. In this case, it is a question of checking whether the gap between countries has widened or narrowed. The theories surrounding this concept of inequality between countries are therefore the theories of growth, which will be explained later. The second concept of income inequality is used to assess the gaps between rich and poor within countries. The two most commonly invoked theories are the Kuznets curve and the Heckscher-Ohlin-Samuelson (HOS) theorem (Milanovic, 2011).

Since the work of Barro and Sala-i-Martin (1990, 1991 and 1992), and especially that of Quah (1993), the 
literature on the question of the evolution of income disparities between countries has become abundant. While the work of these authors has inspired many researchers, it should be noted that other scientists before them (Easterlin, 1960; Borts \& Stein, 1964; Streissler, 1979; Barro, 1984; Baumol, 1986; Dowrick \& Nguyen, 1989) had already addressed the problem. However, this literature review will only consider much more recent studies, starting with Marques and Soukiazis (1998). But before doing so, it is worth pointing out that the question of the evolution of income disparities among countries is part of a more global issue, that of convergence. From a theoretical point of view, the convergence debate is driven by two main competitive theories: neoclassical growth theory (Solow, 1956) and endogenous growth theory (Romer, 1986). While the first of these theories predicts economic convergence, the second rejects this idea. That said, Marques \& Soukiazis (op. cit.) study the sigma-convergence between 12 European Union countries over the period 1975-1995. They also carry out sub-period analyses. Their results show that there is sigma-convergence over two sub-periods: the 1975-1982 sub-period characterised by a significant reduction in per capita income dispersion and the 1986-1991 sub-period marked by a small decrease in per capita income disparities among countries. Marques and Soukiazis (op. cit.) also find that there is a divergence in per capita income over the 1983-1985 sub-period and another divergence over the 1991-1995 sub-period. For the entire study period, these two researchers find that the dispersion of per capita income among countries increases in absolute terms.

Diop (2002) examines the sigma-convergence of the economies of the Economic Community of West African States (ECOWAS) over the period 1975-2001 using Figureical analysis. He concludes that there is no convergence of real GDP per capita among ECOWAS countries. Diop (op. cit.) refines his analysis by considering on the one hand WAEMU countries and on the other hand non-WAEMU ECOWAS countries. His results show an overall trend towards a reduction in the standard deviation of real GDP per capita in the WAEMU countries, thus reflecting a real convergence of these economies over the analysis period. They also show a lack of real convergence for non-WAEMU countries.

Guetat and Serranito (2009) analyse the question of the convergence of incomes in the MENA (Middle East and North African) countries towards the income level of Southern European countries over the period 1960-2003. For this purpose, these authors use sigma-convergence and polynomial beta-convergence tests of Chatterji to assess convergence. They also apply segmented trend tests of Bai and Perron (2003) to the problem of sigma-convergence. Their results show that the sigma-convergence process is not uniform over time. Guetat $\&$ Serranito (op. cit.) also find that there is a convergence movement of MENA countries towards the income level of Southern European countries only over the period from the first oil shock to the oil counter-shock.

Combey and Mally (2010) study the evolution of the dispersion of the logarithm of real GDP (Gross Domestic Product) per capita of WAEMU countries (except Guinea-Bissau) over the period 1997-2008. Their analysis is based on a Figureical representation that shows an overall trend towards a reduction in the standard deviation of real GDP per capita in the WAEMU countries, reflecting a real convergence of these economies over the period 1997-2008. These researchers also note that the reduction in dispersion over the period 1997-2008 is mainly due to the increasing evolution of real GDP per capita in Senegal, Benin, Burkina and Niger towards that of Ivory Coast which remains relatively constant. For them, this finding suggests that the convergence observed is more the result of a catching up of the real GDP per capita of rich countries by those of poor countries. Despite the overall evolution they observed (global trend towards a reduction in the standard deviation of real GDP per capita), Combey and Mally (op. cit.) note that it is possible to detect contrasting evolutions over the different sub-periods they considered. To complete their analysis, the two researchers use the non-parametric Wilcoxon test, which they apply to the following two sub-periods: before the Convergence, Stability, Growth and Solidarity Pact (1997-1999) and under the Pact before the period of entry into the stability phase (2000-2007). The test conducted rejects the null hypothesis of equality of variances at the $5 \%$ threshold in favour of the alternative hypothesis of real convergence of economies under the Convergence, Stability, Growth and Solidarity Pact.

Kumo (2011) analyses sigma-convergence among Southern African Development Community (SADC) member states over the period 1992-2009. Indeed, in order to capture possible convergence between the real income levels of these countries, he calculates the standard deviations of real GDP per capita for the 14 member states over the period concerned. His results indicate that the standard deviation of the logarithm of real per capita income calculated for the year 2009 is higher than that determined for the year 1992. He therefore infers that SADC countries, with the exception of Zimbabwe, show a lack of sigma-convergence between 1992 and 2009. In order to compare results, Kumo (op. cit.) also uses GDP per capita measured in PPP for his analyses. His results still show that there is no convergence although the standard deviations obtained with GDP per capita measured in PPP are lower than those calculated with real GDP per capita. Kumo (op. cit.) concludes, therefore, 
that disparities in real income levels between SADC countries have in fact increased over this period.

In a study of WAEMU countries, Gbohoui (2013) examines the evolution of per capita income dispersion using a sigma-convergence test. He notes that this evolution is characterised by three major phases. The first period runs from 1980 to 1994 and is marked by a strong trend towards convergence of per capita incomes in all countries towards the Union average. The second period runs from 1995 to 1998. It is characterised by a pronounced divergence in per capita income with a peak in 1998. The last period, from 1999 to 2008, is characterised by a small fluctuation in the per capita income dispersion of the countries in question around 0.52. Gbohoui (op. cit.) attributes the reduction in per capita income inequality in the first period to a fall in per capita GDP in Ivory Coast of around $36 \%$ over this period. He also believes that the great divergence in the second period is linked to both the growth revival in Ivory Coast and the fall in per capita income in Guinea-Bissau between 1997 and 1998. Finally, Gbohoui (op. cit.) attributes the small variation in per capita income dispersion observed after 1999 to small fluctuations in living standards in different countries.

Lopes and Araújo (2016) study the evolution of spatial similarities and disparities in the Iberian Peninsula, using data on GDP per capita of Portuguese and Spanish regions over the period 1995-2012. Their analysis of sigma-convergence uses the coefficient of variation as an indicator of dispersion and relies on the Figureical approach. Their results show that, in the case of the Iberian Peninsula, there is a very slight decrease in the dispersion indicator between 1995 and 2012, with two contradictory trends: an increase (divergence) until 2001, and a decrease (convergence) after that year. They also indicate that the dispersion of regional GDP per capita is greater in Portugal (coefficient of variation of about 0.29) than in Spain (coefficient of variation of about 0.21).

Hendajany, Saepudin, and Suaesih (2017) examine the issue of sigma-convergence for Indonesia as a whole and for the provinces of Indonesia over the period from 1986 to 2010. Specifically, the work of these authors was to check whether or not sigma-convergence occurred in Indonesia and also to study it based on the calculation and analysis of the dispersion of GDPR (gross regional domestic product) per capita of the regions of Indonesia. Their results show that for many individual provinces as well as for Indonesia as a whole, sigma-divergence has occurred between 1986 and 2010.

Again for Indonesia, Kurniawati and Lestari (2019) use data from four provinces in Kalimantan over the period 2002-2016 and use the coefficient of variation to analyse regional income inequality, government expenditure and revenue through the concept of sigma-convergence. Their results confirm that there has been a sigma-convergence of regional income, public revenue and expenditure at different times. Regional income and public expenditure converged in 2012, while public revenue concentrated relatively faster in 2006 . They also show that inequality in government revenue is decreasing faster compared to regional income and government expenditure.

\section{Methodology for the study of income disparities among countries}

The approach used is that of sigma-convergence. It is based on the calculation and comparison of the value of the standard deviation of the logarithm of GDP per capita at the beginning and end of the study period. The value of the standard deviation is obtained from the following relationship (Guetat \& Serranito, 2009):

$$
\sigma_{\mathrm{t}}=\left[\mathrm{N}^{-1} \sum_{\mathrm{i}=1}^{\mathrm{N}}\left(\log \left(\mathrm{Y}_{\mathrm{it}}\right)-\left(\mathrm{N}^{-1} \sum_{\mathrm{k}=1}^{\mathrm{N}} \log \left(\mathrm{Y}_{\mathrm{kt}}\right)\right)\right)^{2}\right]^{\frac{1}{2}}
$$

with

$\mathrm{N}$ : the number of countries in the group ;

$\mathrm{Y}_{\mathrm{it}}$ : the GDP per capita of country $i$ at date $t$;

$\mathrm{Y}_{\mathrm{kt}}$ : the GDP per capita of country $\mathrm{k}$ at date $\mathrm{t}$;

If $\sigma_{t+T}<\sigma_{t}$, the hypothesis of sigma-convergence is verified. In this case, the gap between countries tends to narrow. Beyond this theoretical result, which compares the standard deviation at the final date to that at the initial date to assess economic convergence in the sense of sigma, the empirical studies take into account all the intermediate dates. This allows for a better understanding of the dynamics of income distribution within the economies studied.

In practice, there are two procedures for testing sigma-convergence: Figureical analysis and formal test. Figureical analysis consists of observing the evolution of the standard deviation over time.

As for the formal test, it starts with the following equation: 


$$
\sigma_{\mathrm{t}}=\alpha+\gamma \mathrm{t}+\mathrm{v}_{\mathrm{t}}
$$

with

$\mathrm{t}$ : the time;

$Y:$ the coefficient to be estimated;

a : a constant;

$\mathrm{v}_{\mathrm{t}}:$ the error term.

To achieve the first specific objective, equation (2) will be estimated over the entire study period (1980-2019).

If the coefficient of the time trend is negative and significant $(\gamma<0)$, then the disparities in per capita income among the different economies are reduced over time. In this case, there is convergence in the sense of sigma between the economies considered.

In order to achieve the second specific objective, the study period (1980-2019) will first be divided into two sub-periods, namely the sub-period 1980-1993 and the sub-period 1994-2019. It will then be necessary to estimate equation (2) over the two sub-periods and to compare the convergence dynamics before and after 1994. In other words:

$$
\left\{\begin{array}{l}
\sigma_{t}=a_{1}+\gamma_{1} t+v_{t}, \text { if } t=1980, \ldots, 1993 \\
\sigma_{t}=a_{2}+\gamma_{2} t+v_{t}, \text { if } t=1994, \ldots, 2019
\end{array}\right.
$$

After estimating the linear trend model, further analyses to make the results more consistent will be carried out by considering two other specifications: a model with a quadratic trend and a model with a kinked trend.

\section{The model with a quadratic trend}

This model takes the following form:

$$
\sigma_{\mathrm{t}}=\alpha+\gamma_{1} \mathrm{t}+\gamma_{2} \mathrm{t}^{2}+\mathrm{v}_{\mathrm{t}}
$$

with

$\mathrm{t}$ : the time;

$\gamma_{1}$ and $\gamma_{2}$ : the coefficients to be estimated;

a : a constant;

$\mathrm{v}_{\mathrm{t}}$ : the error term.

This specification will be used to check whether income disparities differ between sub-periods.

\section{$\checkmark \quad$ The model with a kinked trend}

It takes the following form :

$$
\sigma_{t}=\left(a_{1}+a_{2} d_{t}\right)+\left(\gamma_{1}+\gamma_{2} d_{t}\right) t+v_{t}
$$

with

$\mathrm{t}$ : the time;

$d_{t}$ : an indicator variable $\left\{\begin{array}{l}d_{t}=0, \text { if } t=1980, \ldots, 1993 \\ d_{t}=1, \text { if } t=1994, \ldots, 2019\end{array}\right.$

$\mathrm{a}_{1}:$ a constant;

$\mathrm{a}_{2}, \gamma_{1}$ and $\gamma_{2}$ : the coefficients to be estimated;

$\mathrm{v}_{\mathrm{t}}$ : the error term.

Here, it will be a matter of testing if $\alpha_{2}=\gamma_{2}=0$ to see if there is a difference in income disparity between the sub-periods. However, for practical reasons related to econometric estimations, equation (5) will be transformed into the following form:

$$
\sigma_{t}=a_{1}+a_{2} d_{t}+\gamma_{1} t+\gamma_{2} d_{t} t+v_{t}
$$

Beyond all the equations presented, further analysis will be carried out by performing two comparison tests: the Student test and the Wilcoxon (Mann-Whitney) test. 


\section{$\checkmark$ The Student test}

The Student test is a parametric test that tests whether two group means can be considered significantly different at an $\alpha$ error level. In other words, it consists of testing the null hypothesis $\mu_{1}=\mu_{2}$ when $\sigma_{1}$ and $\sigma_{2}$ are unknown against the alternative hypothesis.

The alternative hypothesis can take three forms :

- $\mathrm{H}_{\mathrm{a}}: \mu_{1}<\mu_{2}$ (Left-tailed test)

- $\mathrm{H}_{\mathrm{a}}: \mu_{1} \neq \mu_{2}$ (Two-tailed test)

- $\mathrm{H}_{\mathrm{a}}: \mu_{1}>\mu_{2}$ (Right-tailed test)

The Student test statistic is written :

$$
\mathrm{t}=\frac{\mathrm{m}_{1}-\mathrm{m}_{2}}{\left\{\frac{\left(\mathrm{n}_{1}-1\right) \mathrm{s}_{1}^{2}+\left(\mathrm{n}_{2}-1\right) \mathrm{s}_{2}^{2}}{\mathrm{n}_{1}+\mathrm{n}_{2}-2}\right\}^{1 / 2}\left(\frac{1}{\mathrm{n}_{1}}+\frac{1}{\mathrm{n}_{2}}\right)^{1 / 2}}
$$

with

$\mathrm{m}_{1}$ and $\mathrm{m}_{2}$ : the means in each of the 2 groups;

$\mathrm{n}_{1}$ : the number of individuals in group 1 ;

$\mathrm{n}_{2}$ : the number of individuals in group 2 ;

$\mathrm{s}_{1}^{2}$ : the estimated variance of group 1 ;

$\mathrm{s}_{2}^{2}$ : the estimated variance of group 2 .

This statistic follows a Student law with $n_{1}+n_{2}-2$ degrees of freedom.

The application of the Student test is subject to two conditions: normality and equality of the variances of the samples considered. Normality will be checked here using the Shapiro-Wilk test (Appendix 9 and Appendix 10). The equality of variances will be verified using the Fisher test (Appendix 11).

\section{$\checkmark$ Wilcoxon (Mann-Whitney) test}

The Wilcoxon (Mann-Whitney) test or rank sum test is a non-parametric test that tests the equality of the distributions of two independent sets of values to be compared. If $X_{1}$ and $X_{2}$ are the random variables that relate to these series, the null hypothesis to be tested is $\mathrm{H}_{0}$ : $\mathrm{X}_{1} \sim \mathrm{X}_{2}$. Considering a sample of size $\mathrm{n}_{1}$ from the series for $X_{1}$ and another sample of size $n_{2}$ from the series for $X_{2}$, the data are ranked in ascending order regardless of the samples to which they belong. They are then replaced by their ranks. Where there are ties, they are treated by assigning them the average of the ranks they would occupy. The Wilcoxon (1945) test statistic is the sum of the ranks of the first sample observations:

$$
\mathrm{T}=\sum_{\mathrm{i}=1}^{\mathrm{n}_{1}} \mathrm{R}_{1 \mathrm{i}}
$$

The Mann and Whitney (1947) U-statistic is the number of pairs $x_{1 i}, x_{2 j}$ such that $x_{1 i}>x_{2 j}$. These statistics differ by a constant :

$$
\mathrm{U}=\mathrm{T}-\frac{\mathrm{n}_{1}\left(\mathrm{n}_{1}+1\right)}{2}
$$

It is shown that:

$$
\mathrm{E}(\mathrm{T})=\frac{\mathrm{n}_{1}(\mathrm{n}+1)}{2}
$$

and

$$
\operatorname{Var}(\mathrm{T})=\frac{\mathrm{n}_{1} \mathrm{n}_{2} \mathrm{~s}^{2}}{\mathrm{n}}
$$

where $\mathrm{s}$ is the standard deviation of the combined ranks, $r_{i}$, for both groups:

$$
\mathrm{s}^{2}=\frac{1}{\mathrm{n}-1} \sum_{\mathrm{i}=1}^{\mathrm{n}}\left(\mathrm{r}_{\mathrm{i}}-\overline{\mathrm{r}}\right)^{2}
$$

Mann and Whitney (1947) showed, with respect to the distribution of the U-statistic, that a normal 
approximation can be made if the number of observations for each of the two subgroups is greater than eight (in other words, $\mathrm{n}_{1}>8$ and $\mathrm{n}_{2}>8$ ).

Using a normal approximation, we calculate :

$$
\mathrm{z}=\frac{\mathrm{T}-\mathrm{E}(\mathrm{T})}{\sqrt{\operatorname{Var}(\mathrm{T})}}
$$

The data used in this study are secondary data. These are also annual data from the IMF's World Economic Outlook (WEO) 2009, 2017, 2018 and 2020. They are expressed in PPP dollars, as this is the unit used in most international comparisons of GDP per capita. It is appropriate, in our view, because PPP allows the price effect to be corrected in order to compare GDP per capita relative to different countries with equally different purchasing power. Although WAEMU member countries share a common currency (the CFA franc), price levels are different because national markets are not fully integrated.

The statistical processing of the different data as well as the econometric estimations were done with the STATA 12.0 software.

\section{Results of the Study of Income Disparities among WAEMU Countries and Discussion}

The results will be presented in a first step and discussed in a second step.

4.1 Results

Here, the first step will be to make a Figureical analysis and to propose an outline of the results. Next, the results of the formal test estimates will be presented. Finally, the results of the Student and Mann-Whitney tests will be given.

\subsubsection{Outline of Results from a Figureical Analysis}

Figure 1 first presents the evolution of the standard deviation of the logarithm of GDP per capita (in PPP dollars) in the WAEMU zone between 1980 and 2019. Figure 2 then shows the trend in this same variable over the period 1980-1993. As for Figure 3, it finally illustrates the evolution of the same variable between 1994 and 2019.

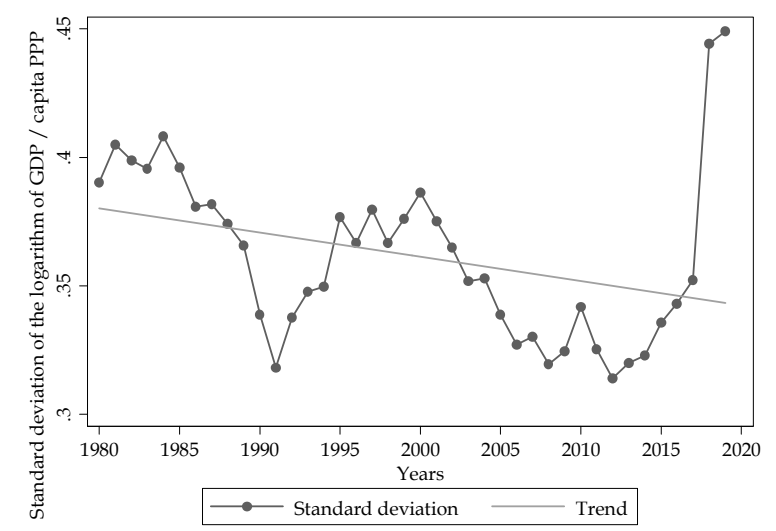

Figure 1. Evolution of the standard deviation computed between 1980 and 2019

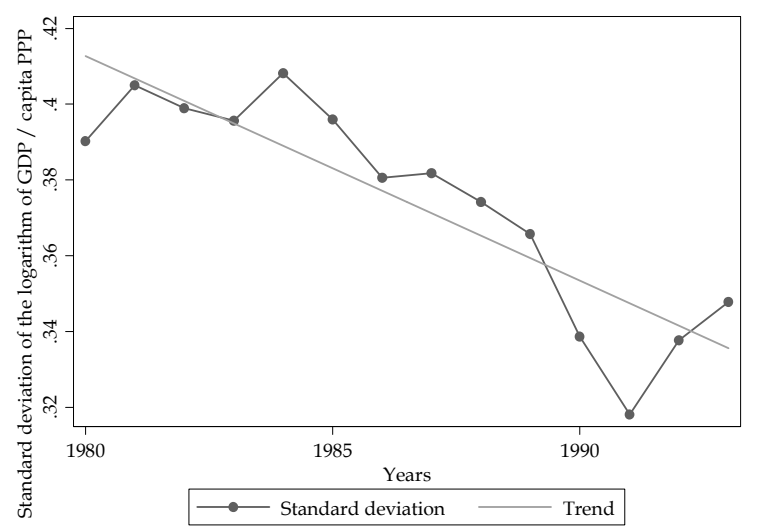

Figure 2. Evolution of the standard deviation calculated between 1980 and 1993 


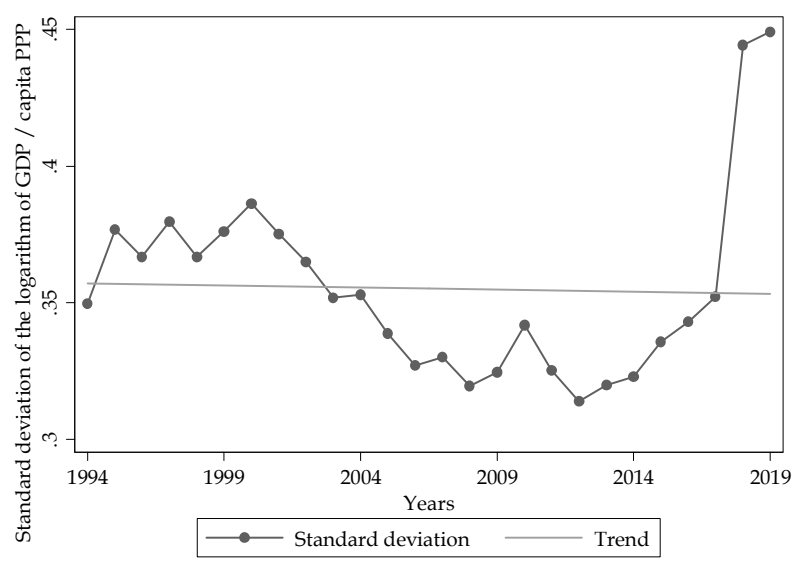

Figure 3. Evolution of the standard computed between 1994 and 2019

To begin with, Figure 1 shows an overall downward trend in the standard deviation with a peak of 0.449 observed in 2019 and a trough of 0.314 that appeared in 2012. This trend reveals that there has been a reduction in income disparities between WAEMU member states over the period 1980-2019.

Figure 2 also points up an overall downward trend in the standard deviation of the logarithm of GDP per capita (in PPP dollars) of WAEMU member countries over the period 1980-1993. The curve is irregular. It is characterised by a peak of 0.408 in 1984 and a trough of 0.318 in 1991 .

Finally, Figure 3 shows an overall downward trend in the standard deviation of the logarithm of GDP per capita (in PPP dollars) of WAEMU member states over the period 1994-2019, despite a recent upturn. The curve has a peak with a standard deviation of 0.449 and a trough with a standard deviation of 0.314 .

\subsubsection{Results of the Formal Test Estimates}

\subsubsection{Results of the Linear Trend Equation Estimations}

\section{$\checkmark$ Results of the estimation of the linear trend equation by the Ordinary Least Squares method}

The results of the estimates are presented in the following table :

Table 1. Results of the estimation of the linear trend equation by the Ordinary Least Squares method (dependent variable: standard deviation)

\begin{tabular}{cccc}
\hline Parameters & $1980-1993$ & $1994-2019$ & $1980-2019$ \\
\hline Constant & 12.1517 & 0.6604 & 2.2504 \\
t & $(0.0000)^{* * *}$ & $(0.7230)$ & $(0.0140)^{* *}$ \\
& -0.0059 & -0.0002 & -0.0009 \\
R-squared & $(0.0000)^{* * *}$ & $(0.8700)$ & $(0.0370)^{* *}$ \\
Adj. R-squared & 0.7593 & 0.0011 & 0.1096 \\
Prob $>$ F & 0.7392 & -0.0405 & 0.0862 \\
DW & 0.0000 & 0.8697 & 0.0369 \\
\hline
\end{tabular}

Note. The figures in brackets are the p-values. * significant at $10 \%$ level; ** significant at $5 \%$ level; *** significant at $1 \%$ level.

For the equation estimated over the period 1980-1993, the main diagnostic tests carried out do not reveal any problems; only the Durbin-Watson autocorrelation test shows that the errors in the trend equation are positively correlated (Appendix 2). This situation requires that the autocorrelation be corrected. For this purpose, the estimation will be repeated using the Prais-Winsten method.

For the equations estimated over the period 1980-2019 and over the period 1994-2019, the normality test indicates that the distribution of the residuals is not normal (Appendix 2). In this context, the estimations at the level of these two periods will be redone using the Bootstrap in order to correct the standard errors.

\section{$\checkmark$ Results of the estimation of the linear trend equation by the Prais-Winsten method and by the Bootstrap}

The results of the estimations after the various corrections are reported in the following table : 
Table 2. Results of the estimation of the linear trend equation by the Prais-Winsten method (period 1980-1993) and by the Bootstrap technique (period 1980-2019 and period 1994-2019) (dependent variable: standard deviation)

\begin{tabular}{cccc}
\hline Parameters & $1980-1993$ & $1994-2019$ & $1980-2019$ \\
\hline Constant & 10.4735 & 0.6604 & 2.2504 \\
& $(0.0030)^{* * *}$ & $(0.0000)^{* * *}$ & $(0.0150)^{* * *}$ \\
$\mathrm{t}$ & & & -0.0009 \\
& -0.0051 & -0.0002 & $(0.0420)^{* *}$ \\
R-squared & $(0.0030)^{* * *}$ & $(0.0000)^{* * *}$ & 0.1096 \\
Adj. R-squared & & & 0.0862 \\
Prob>F/Prob>chi2 & 0.9211 & -0.0405 & 0.0420 \\
DW & 0.9146 & 0.0000 & - \\
\hline
\end{tabular}

Note. The figures in brackets are the p-values.

* significant at $10 \%$ level; ** significant at $5 \%$ level; *** significant at $1 \%$ level.

The results of the Durbin-Watson autocorrelation test carried out on the model re-estimated by the Prais-Winsten method over the period 1980-1993 indicate that the autocorrelation has been corrected (Appendix 3). The coefficients of all estimated equations are all significant at the 5\% level. All regressions are also globally significant at the $5 \%$ level. However, the coefficients of determination for the equations estimated over the periods 1994-2019 and 1980-2019 are low. For the period 1994-2019, it is almost zero (0.0011) and the adjusted coefficient of determination is negative (-0.0405). In these circumstances, and also to make the results more robust, other specifications will be considered including a model with a quadratic trend and a model with a kinked trend. The analysis will also be completed by the two comparison tests already presented (the Student test and the Mann-Whitney test).

4.1.2.2 Model Estimation Results with a Quadratic Trend

These results are set out in the following table :

Table 3. Results of the estimation of the model with a quadratic trend by the Ordinary Least Squares method (dependent variable: standard deviation)

\begin{tabular}{cccc}
\hline Parameters & $1980-1993$ & $1994-2019$ & $1980-2019$ \\
\hline Constant & -1615.3840 & 1692.8330 & 510.8353 \\
& $(0.1330)$ & $(0.0010)^{* * *}$ & $-0020)^{* * *}$ \\
$\mathrm{t}$ & 1.6327 & -1.6869 & $(0.5097$ \\
$\mathrm{t}^{2}$ & $(0.1320)$ & $0.0010)^{* * *}$ & 0.0001 \\
& -0.0004 & $(0.0010)^{* * *}$ & $(0.0020)^{* * *}$ \\
R-squared & $(0.1300)$ & 0.3926 & 0.3211 \\
Adj. R-squared & 0.8063 & 0.3398 & 0.2844 \\
Prob $>$ F & 0.7711 & 0.0032 & 0.0008 \\
DW & 0.0001 & 0.6032 & 0.4647 \\
\hline
\end{tabular}

Note. The figures in brackets are the p-values.

* significant at $10 \%$ level; ** significant at $5 \%$ level; *** significant at $1 \%$ level.

The results in the table above raise some issues. The validity tests carried out show that the distribution of the residuals of the equation regressed on the period 1980-2019 does not follow the normal distribution. They also indicate a heteroskedasticity problem in the estimated equation over the 1980-1993 sub-period, and both a heteroskedasticity problem and an error autocorrelation problem over the 1994-2019 sub-period. To remedy these problems, the estimates have been revised. The equation for the period 1980-2019 was therefore re-estimated using the Bootstrap technique. The regression of the 1980-1993 sub-period equation was also redone using the Huber-White method. The equation for the 1994-2019 sub-period was re-estimated using the Newey-West method.

The following results were obtained: 
Table 4. Results of the model estimations with a quadratic trend after correction of the problems revealed by the validity tests (dependent variable: standard deviation)

\begin{tabular}{|c|c|c|c|}
\hline Parameters & 1980-1993 & 1994-2019 & 1980-2019 \\
\hline Constant & $\begin{array}{c}-1615.3840 \\
(0.1660)\end{array}$ & $\begin{array}{c}1692.8330 \\
-\end{array}$ & $\begin{array}{c}0.3618 \\
(0.0000)^{* * * *}\end{array}$ \\
\hline $\mathrm{t}$ & $\begin{array}{c}1.6327 \\
(0.1640)\end{array}$ & $\begin{array}{c}-1.6869 \\
(0.0000)^{* * *}\end{array}$ & $\begin{array}{c}-0.5097 \\
(0.0160)^{* *}\end{array}$ \\
\hline$t^{2}$ & $\begin{array}{l}-0.0004 \\
(0.1630)\end{array}$ & $\begin{array}{c}0.0004 \\
(0.0000)^{* * *}\end{array}$ & $\begin{array}{c}0.0001 \\
(0.0160)^{* *}\end{array}$ \\
\hline R-squared & 0.8063 & $\ldots$ & 0.3211 \\
\hline Adj.R-squared & - & $\overline{ }$ & 0.2844 \\
\hline Prob>F/Prob>chi2 & - & 0.0000 & 0.0000 \\
\hline DW & 1.2453 & - & - \\
\hline
\end{tabular}

Note. The figures in brackets are the p-values. * significant at $10 \%$ level; ** significant at $5 \%$ level; *** significant at $1 \%$ level.

The estimated coefficients of the regression for the sub-period 1980-1993 are not significant. It is therefore impossible under these conditions to make relevant analyses, in particular by comparing the coefficients of the equations for the sub-periods 1980-1993 and 1994-2019. In the end, the model with a quadratic trend does not allow really meaningful conclusions to be drawn.

\subsubsection{Model Estimation Results with a Kinked Trend}

The results of the estimation of the model with a kinked trend by the Ordinary Least Squares method are given in the table below:

Table 5. Estimation results for the model with a kinked trend using the Ordinary Least Squares method (dependent variable: standard deviation)

\begin{tabular}{|c|c|c|c|}
\hline Parameters & Coefficients & $\mathrm{t}$ & $P>|t|$ \\
\hline Constant & $\begin{array}{c}12.1517 \\
(3.9308)^{* * *}\end{array}$ & 3.0900 & 0.0040 \\
\hline $\mathrm{d}_{\mathrm{t}}$ & $\begin{array}{c}-11.4914 \\
(4.2313)^{* *}\end{array}$ & -2.7200 & 0.0100 \\
\hline $\mathrm{t}$ & $\begin{array}{c}-0.0059 \\
(0.0020)^{* * *}\end{array}$ & -3.0000 & 0.0050 \\
\hline $\mathrm{d}_{\mathrm{t}} \mathrm{t}$ & $\begin{array}{c}0.0058 \\
(0.0021)^{* *}\end{array}$ & 2.7200 & 0.0100 \\
\hline R-squared & 0.2610 & - & $\longrightarrow$ \\
\hline Adj. R-squared & 0.1994 & - & $\ldots$ \\
\hline Prob $>$ F & 0.0115 & 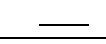 & 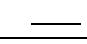 \\
\hline
\end{tabular}

Note. Figures in brackets are standard deviations. * significant at $10 \%$ level; ** significant at $5 \%$ level; *** significant at $1 \%$ level.

After estimating the model with a kinked trend by the Ordinary Least Squares method, the validity tests carried out showed that the distribution of the residuals does not follow the normal distribution (Appendix 8). The estimates were therefore redone using the Bootstrap technique, which led to the following results :

Table 6. Estimation results of the model with a kinked trend using the Bootstrap technique (dependent variable: standard deviation)

\begin{tabular}{|c|c|c|c|}
\hline Parameters & Coefficients & $\mathrm{z}$ & $\mathrm{P}>|\mathrm{z}|$ \\
\hline Constant & $\begin{array}{c}12.1517 \\
(2.3843)^{* * * *}\end{array}$ & 5.1000 & 0.0000 \\
\hline $\mathrm{d}_{\mathrm{t}}$ & $\begin{array}{c}-11.4914 \\
(3.4465)^{* * *} *\end{array}$ & -3.3300 & 0.0010 \\
\hline $\mathrm{t}$ & $\begin{array}{c}-0.0059 \\
(0.0012)^{* * * *}\end{array}$ & -4.9400 & 0.0000 \\
\hline $\mathrm{d}_{\mathrm{t}} \mathrm{t}$ & $\begin{array}{c}0.0058 \\
(0.0017)^{* * *} *\end{array}$ & 3.3400 & 0.0010 \\
\hline R-squared & 0.2610 & - & - \\
\hline Adj. R-squared & 0.1994 & $\longrightarrow$ & $\longrightarrow$ \\
\hline Prob $>$ chi 2 & 0.0000 & 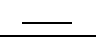 & 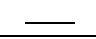 \\
\hline
\end{tabular}


The results obtained give a probability of 0.0005 for the Wald test. Under these conditions, the null hypothesis that $\mathrm{a}_{2}=\gamma_{2}=0$ is rejected at the $5 \%$ level and it is concluded that there is a difference in income disparity between the sub-periods. These results also show that at the $5 \%$ level the estimated model is globally significant and the coefficients of its explanatory variables are all significant. They also indicate that the coefficient on the reform variable $\left(d_{t}\right)$ is negative, which means that this variable has a negative effect on income disparities. In other words, the reforms contribute to reducing the income gap between WAEMU countries. The results also show that the coefficient on the time variable $(\mathrm{t})$ is negative, which means that income disparities between the different states decrease over time. They also yield a positive coefficient for the interaction term $\left(\mathrm{d}_{\mathrm{t}} \mathrm{t}\right)$, with the correlation coefficient between the variables $\mathrm{d}_{\mathrm{t}}$ and $\mathrm{t}$ being 0.8264: this means that the effect of reforms on income disparities increases over time. In order to ensure the robustness of the results, additional analysis methods will be used, namely comparison tests (the Student test and the Mann-Whitney test).

4.1.3 Results of the Student and Wilcoxon (Mann-Whitney) Tests

The results of the comparison tests are presented in the following table:

Table 7. Results of the Student and Mann-Whitney tests

\begin{tabular}{cc}
\hline Comparison tests & $1980-1993$ versus 1994-2019 \\
\hline Student test & $8.9737 * * *$ \\
Wilcoxon (Mann-Whitney) test & $2.1270^{* *}$ \\
\hline
\end{tabular}

Note. The values reported in the table are the t-statistic for the Student test and the $\mathrm{z}$-statistic for the Mann-Whitney test.

* significant at $10 \%$ level; ** significant at $5 \%$ level; *** significant at $1 \%$ level.

The probability of the Student test is 0.0000 . Under these conditions, the null hypothesis of equality of the means of the inequality indicator before and after 1994 is rejected at the 5\% threshold in favour of the alternative hypothesis according to which the mean of the standard deviation of the logarithm of per capita income in the second period is lower than that in the first period. The probability of the Mann-Whitney test is 0.0334 . This makes it possible to reject, at the 5\% threshold, the null hypothesis that the distributions of standard deviations of the logarithm of per capita incomes of WAEMU countries are identical before and after 1994.

\subsection{Discussion}

As the results of the estimations of the model with a quadratic trend do not allow us to draw sufficiently significant conclusions with regard to the objectives set by the study, the discussion will only focus on the results of the estimations relating to the model with a kinked trend and those of the comparison tests (the Student test and the Mann-Whitney test), and to a lesser extent those of the linear trend equation. This being, the estimations of this linear trend model yield a coefficient of the time trend that is both negative $(-0.0009)$ and significant at the 5\% statistical level over the period 1980-2019. The hypothesis of sigma-convergence is therefore verified. Under these conditions, disparities in per capita income between the different WAEMU economies are narrowing over time. As regards the comparison of convergence dynamics before and after 1994, one should remain rather cautious given the very poor quality of the adjustment over the 1994-2019 sub-period. The results of estimating the model with a kinked trend show that income disparities between WAEMU member states are narrowing over time and that reforms are helping to reduce the income gap between these countries. The results of this model also indicate that the effect of reforms on income disparities becomes more important over time. The Student mean comparison test also shows that the mean of the standard deviation of the logarithm of per capita income in the second period is lower than in the first sub-period. This result is corroborated by the Mann-Whitney test, which rejects the null hypothesis that the distributions of standard deviations of the logarithm of per capita incomes of the WAEMU states are identical before and after 1994. Basically, these two comparison tests prove that there is a greater decrease in per capita income disparities between the economies in question after 1994. In this case, it can be said that the reforms implemented within the WAEMU since 1994 have certainly contributed in part to a reduction in disparities in per capita income between the economies of this zone. Since a careful analysis of the data also shows both a stagnation of Ivory Coast's GDP per capita (in PPP dollars) over the period 1999-2009 and a decline in its GDP per capita (in PPP dollars) over the period 2010-2011, due to the successive crises that have shaken the country since 1999. A closer look at the data shows that the reduction in per capita income disparities between WAEMU economies observed over the period 1980-2019 can be explained in part by the strong progression of per capita incomes in Senegal, Benin and Mali towards that of Ivory Coast (Appendix 1). It also indicates that this can be attributed in part to the steady increase in Burkina's per capita income between 1980 and 2019, while Togo's and Niger's per capita income increased only slightly (Appendix 1). 
It is important to note that the results obtained are in line with those of Combey and Mally (2010) who show an overall trend towards a reduction in the standard deviation of real GDP per capita in the WAEMU countries over the period 1997-2008. They are also in line with those of Diop (2002) who also reveals an overall downward trend in the standard deviation of real GDP per capita in the WAEMU countries between 1975 and 2001. Not only did this work confirm the findings of Combey and Mally (op. cit.) and Diop (op. cit.), but it also highlighted the positive effects of the reforms implemented since 1994 in the WAEMU zone.

\section{Conclusion}

The objective of this study was to examine the evolution of income disparities between the member states of the West African Economic and Monetary Union (WAEMU), and to verify whether the reforms (reinforcement of harmonisation policies within the framework of the implementation of the WAEMU treaties, economic reforms that accompanied the devaluation of the CFA franc, etc.) undertaken in this Union since 1994 have had a favourable impact on income inequalities between nations.

The approach used is that of sigma-convergence which has become popular since the work done by Danny Quah in the early 1990s. It consists of studying the evolution of income dispersion over time. Here, the standard deviation has been used to measure income dispersion. Figureical studies were made and formal tests performed (linear trend equation, quadratic trend model, kinked trend model and comparison tests). In some cases, the analyses were conducted by considering the entire study period (1980-2019) on the one hand and by distinguishing two sub-periods (the sub-period 1980-1993 and the sub-period 1994-2019) on the other. In other cases, they were instead conducted by simply taking into account the entire study period (1980-2019) but including a dummy variable in the model that takes the value 1 from 1994 onwards and the value 0 before 1994 . The data used are annual secondary data from the IMF's World Economic Outlook (WEO) 2009, 2017, 2018 and 2020. The results of the study showed that WAEMU member states experienced a reduction in income inequality over the period 1980-2019 as well as over the sub-periods 1980-1993 and 1994-2019. They also pointed out that the reforms implemented within WAEMU since 1994 have contributed in part to a reduction in per capita income disparities among the economies of this zone. In view of the results obtained, the study recommends that the Community authorities continue to implement reforms and strengthen the coordination and harmonisation of the Union's economic, financial and trade policies.

Although the standard deviation is generally used as a measure of dispersion, other indices (coefficient of variation, Theil index, etc.) exist and have interesting properties. In terms of perspective, it would be worthwhile to change the approach by using some of these indices as a measure of dispersion to examine the issue of the evolution of income disparities among WAEMU member countries.

\section{References}

Allaoui, Z., \& Chkir, A. (2006). Mondialisation, convergence et croissance économique: Une analyse par les données de panel. MPRA Paper, 7306, Munich Personal RePEc Archive (MPRA). Retrieved from http://mpra.ub.uni-muenchen.de/7306/

Bai, J., \& Perron, P. (2003). Computation and Analysis of Multiple Structural Change Models. Journal of Applied Econometrics, 1-22. https://doi.org/10.1002/jae.659

Barro, R. J. (1984). Macroeconomics (1st ed.). Wiley, New York.

Barro, R. J., \& Sala-i-Martin, X. (1990). Economic Growth and Convergence Across the United States. National Bureau of Economic Research working paper, 3419. https://doi.org/10.3386/w3419

Barro, R. J., \& Sala-i-Martin, X. (1991). Convergence Across States and Regions. Brooking Papers on Economic Activity, 22(1), 107-182. https://doi.org/10.2307/2534639

Barro, R. J., \& Sala-i-Martin, X. (1992). Convergence. Journal of Political Economy, 100(2), $223-251$. https://doi.org/10.1086/261816

Baumol, W. J. (1986). Productivity Growth, Convergence, and Welfare: What the Long Run Data Show. American Economic Review, 76, 1072-1085.

Borts, G. H., \& Stein, J. L. (1964). Economic Growth in a Free Market. Columbia University Press, New York.

Combey, A., \& Mally, K. (2010). Impact du pacte de convergence, de stabilité et de croissance sur la convergence réelle dans l'UEMOA. MPRA Paper, 24408, Munich Personal RePEc Archive (MPRA).

Commission Économique pour l'Afrique. (2007). Convergence économique en Afrique Centrale. Rapport, Commission Économique pour l'Afrique/ Bureau Sous-Régional pour l'Afrique Centrale, octobre. 
Diop, P. L. (2002). Convergence nominale et convergence réelle: Une application des concepts de $\sigma$-convergence et de $\beta$-convergence aux économies de la CEDEAO. Notes d'Information et Statistiques, 531, BCEAO.

Dowrick, S., \& Nguyen, D. (1989). OECD Comparative Economic Growth 1950-85: Catch-Up and Convergence. American Economic Review, 79, 1010-1030.

Easterlin, R. A. (1960). Interregional Differences in Per Capita Income, Population, and Total Income, 1840-1950. In Conference on Research in Income and Wealth, NBER (National Bureau of Economic Research) Studies in Income and Wealth, 24.

Gannoun, I. (2007). Évaluation de la convergence de l'efficience productive des secteurs bancaires d'un nombre de pays émergents (la Tunisie, le Maroc, l'Egypte, le Liban, le Qatar, la Jordanie, le Mexique, l'Argentine, la Malaisie, l'Indonésie, Singapore, la Thaïlande, la Corée du Sud, l'Inde et la Turquie). Institut Supérieur de Gestion de Sousse, Université de Sousse.

Gbetnkom, D. (2007). Réformes commerciales et convergence réelle dans la CEMAC. Actes de la Conférence 2007 (Conférence Économique pour l'Afrique), Addis-Abeba, 15-17 novembre 2007.

Gbohoui, W. (2013). Economic Integration in WAEMU: Will the Multilateral Monitoring Mechanism lead to Growth and Welfare Convergence? Paper prepared for the African Economic Conference (AEC) on «Regional Integration in Africa». Retrieved from http://www.afdb.org/uploads/tx_llafdbpapers/Economic_Integration_in_WAEMU.pdf

Guetat, I., \& Serranito, F. (2009). Convergence des pays de la région MENA vers le niveau de revenu des pays du sud de l'Europe: Une évaluation empirique. Économie appliquée, 62(2), 33-67.

Hendajany, N., Saepudin, D., \& Suaesih, A. (2017). Beta Convergence and Sigma Convergence: Evidence from Indonesian District-Level Data. Jurnal Ekonomi Kuantitatif Terapan (JEKT), 10(1), 10-25. https://doi.org/10.24843/JEKT.2017.v10.i01.p03

Kumo, W. L. (2011). Growth and Macroeconomic Convergence in Southern Africa. Working Paper Series, 130, African Development Bank, Tunis, Tunisia.

Kurniawati, S., \& Lestari, N. (2019). Sigma Convergence and VECM Approach in Explaining the Relationship among Macro Variables in Indonesia. Journal of Business and Economics Review, 4(4), 156-162. https://doi.org/10.35609/jber.2019.4.4(2)

Lopes, J. C., \& Araújo, T. (2016). GeoFigureic and DemoFigureic Determinants of Regional Growth and Convergence: A Network Approach. Revista Portuguesa de Estudos Regionais, 43, 35-49. http://www.apdr.pt/siterper/numeros/RPER43/43.3.pdf

Mann, H. B., \& Whitney, D. R. (1947). On a Test of Whether One of Two Random Variables is Stochastically Larger than the Other. Annals of Mathematical Statistics, 18(1), 50-60. https://doi.org/10.1214/aoms/1177730491

Marques, A. \& Soukiazis, E. (1998). Per Capita Income Convergence Across Countries and Across Regions in the European Union: Some New Evidence. Paper presented at the International Meeting of European Economy.

Milanovic, B. (2011). Plus ou moins. Finances \& Développement, 48(3), 6-11.

Ndiaye, M. B. O. (2006). UEMOA: Une intégration économique à deux vitesses à travers des clubs de convergence. Communication aux $7^{\text {èmes }}$ journées scientifiques du réseau «Analyse Économique et Développement de l'AUF», Paris, les 7 et 8 septembre 2006.

Niang, A. A. (2010). Croissance et convergence économique en Afrique: l'impact des effets spatiaux. MPRA Paper, 24059, Munich Personal RePEc Archive (MPRA).

Quah, D. T. (1993). Galton's Fallacy and Tests of the Convergence Hypothesis. The Scandinavian Journal of Economics, 95, 427-443. https://doi.org/10.2307/3440905

Romer, P. (1986). Increasing Returns and Long-Run Growth. Journal of Political Economy, 94, 1002-1037. https://doi.org/10.1086/261420

Solow, R. M. (1956). A Contribution to the Theory of Economic Growth. Quaterly Journal of Economics, 70(1), 65-94. https://doi.org/10.2307/1884513

Streissler, E. (1979). Growth Models as Diffusion Processes: II. Empirical Implications. Kykios, 32(3), 571-586. https://doi.org/10.1111/j.1467-6435.1979.tb02604.x 
Wilcoxon, F. (1945). Individual Comparisons by Ranking Methods. Biometrics, 1(6), $80-83$. https://doi.org/10.2307/3001968

\section{Appendix}

Appendix 1. Evolution of GDP per capita in the WAEMU zone between 1980 and 2019

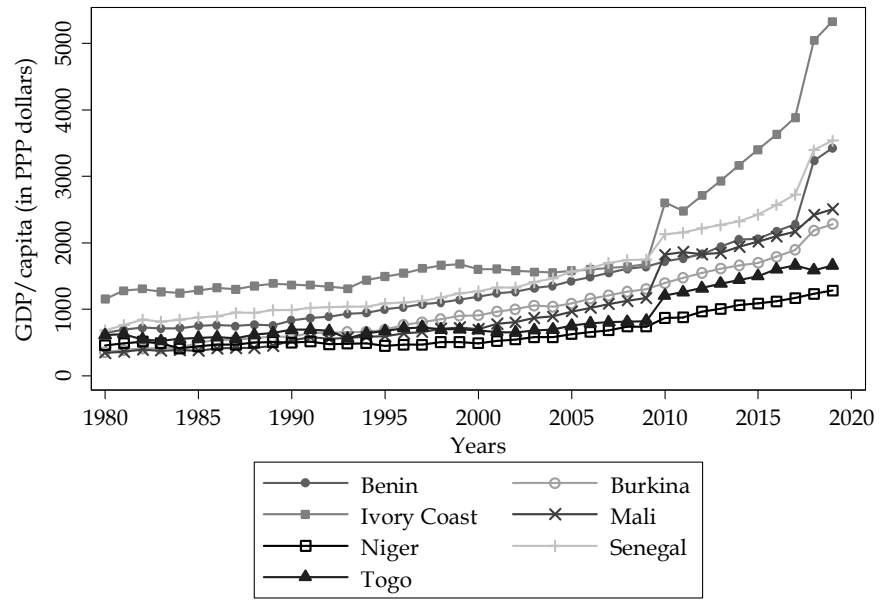

\section{Appendix 2. Results of validity tests of the linear trend equation estimated by the Ordinary Least Squares method}

The probability of the normality test performed on the residuals of the linear trend equation estimated over the period 1980-2019 is 0.00016. Here, at the 5\% threshold, we reject the null hypothesis of normality of the residuals. Applying this test on the residuals of the linear trend equation estimated over the period 1980-1993 gives a probability of 0.28022 . In this case, the null hypothesis of normality of the residuals at the $5 \%$ threshold cannot be rejected. This result is further confirmed by the Figure in Appendix 4 where the theoretical normal distribution is represented by the grey diagonal and the residuals of the linear trend equation by the grey points. Performing the same test on the residuals of the linear trend equation estimated over the period 1994-2019 results in a probability of 0.00151 . Therefore, at the $5 \%$ threshold, the null hypothesis of normality of the residuals is rejected.

Applying the Breusch-Pagan/Cook-Weisberg test to the linear trend equation over the period 1980-1993 gives a probability of 0.6990 . Under these conditions, the null hypothesis of homoscedasticity of the residuals cannot be rejected at the $5 \%$ level.

Over the period 1980-1993, the value of the Durbin-Watson statistic is DW $=1.000$. The Durbin-Watson table reading, at the $5 \%$ threshold with $\mathrm{n}=14$ and $\mathrm{k}^{\prime}=1$, indicates $\mathrm{d}_{\mathrm{L}}=1.045$ and $\mathrm{d}_{\mathrm{U}}=1.350$. We find that $\mathrm{DW}<\mathrm{d}_{\mathrm{L}}$, which means that the errors are positively correlated. This situation requires that the autocorrelation be corrected. For this purpose, the estimates for this period will be repeated using the Prais-Winsten method.

The Breusch-Pagan/Cook-Weisberg and Durbin-Watson tests were not used to test the validity of the estimated linear trend equation over the periods 1980-2019 and 1994-2019, as the normality of the residuals is one of the assumptions governing the application of these tests.

\section{Appendix 3. Verification of the autocorrelation correction after re-estimation of the linear trend equation by the Prais-Winsten method}

Calculating the value of the Durbin-Watson statistic over the period 1980-1993 gives $\mathrm{DW}=1.5069 \simeq 1.507$. On the other hand, we have $d_{U}=1.350$. This results in $4-d_{U}=4-1.350=2.650$. We note that $d_{U}<D W<4-d_{U}$, which means that the autocorrelation problem no longer arises. 
Appendix 4. Normality test of the residuals of the linear trend equation (1980-1993)

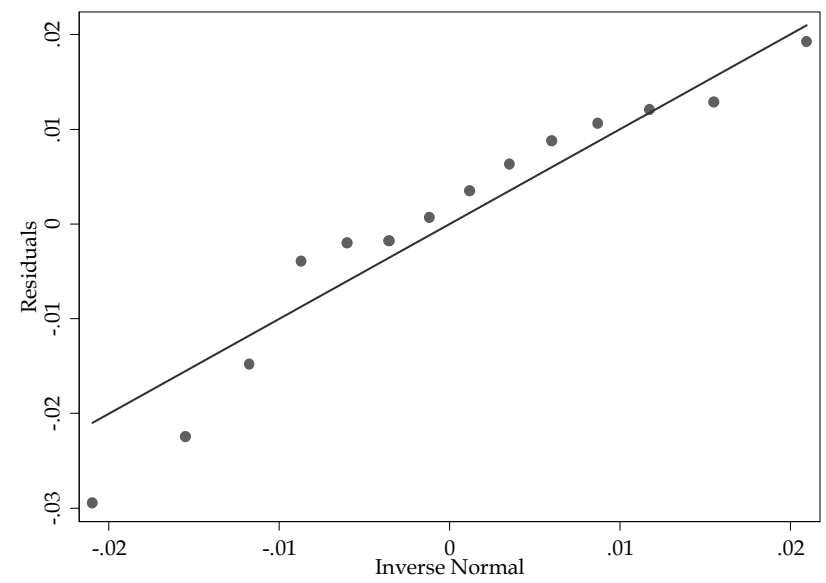

\section{Appendix 5. Results of the validity tests of the model with a quadratic trend estimated by the Ordinary Least Squares method}

The probability of the normality test done on the residuals of the model with a quadratic trend estimated over the period 1980-2019 is 0.04978, which is less than 0.05. The null hypothesis of normality of the residuals is, in this case, rejected at the 5\% threshold. Performing this normality test on the residuals of the model with a quadratic trend estimated over the period 1980-1993 yields a probability of 0.43793 . At the $5 \%$ level, the null hypothesis of normality of the residuals cannot be rejected. This result is further evidenced by the Figure in Appendix 6 . Applying the same normality test on the residuals of the model with a quadratic trend estimated over the period 1994-2019 gives a probability of 0.62095. Under these circumstances, at the 5\% level, the null hypothesis of normality of the residuals of the model in question cannot be rejected over the period in question. As in the previous case, this result is further confirmed by the Figure in Appendix 7.

Here, the Breusch-Pagan/Cook-Weisberg test was used to check for heteroscedasticity with respect to the model with a quadratic trend. Its implementation over the period 1980-2019 is inadequate, since the residuals of the estimated model do not follow the normal distribution. Performing this test over the period 1980-1993 gives a probability of 0.0221 . In this context, the null hypothesis of homoscedasticity of the residuals is rejected at the $5 \%$ threshold. There is therefore a problem of heteroscedasticity at this level which will be corrected. Over the period 1994-2019, the application of the Breusch-Pagan/Cook-Weisberg test provides a probability of 0.0043. In this case, the null hypothesis of homoscedasticity of the residuals is rejected at the 5\% threshold. There is also a problem of heteroscedasticity here which will have to be remedied.

To check the autocorrelation problem, the Durbin-Watson test was used. However, due to the non-normal distribution of the model's residuals with an estimated quadratic trend over the period 1980-2019, its use over the period in question is inappropriate. On the other hand, over the period 1980-1993 where this test is applicable, the value of the Durbin-Watson statistic is $\mathrm{DW}=1.2453$. The Durbin-Watson table reading, at the 5\% threshold with $\mathrm{n}=14$ and $\mathrm{k}^{\prime}=2$, shows that $\mathrm{d}_{\mathrm{L}}=0.905$ and $\mathrm{d}_{\mathrm{U}}=1.551$. We note that $\mathrm{d}_{\mathrm{L}}<\mathrm{DW}<\mathrm{d}_{\mathrm{U}}$. We are therefore in the zone of doubt. But in practice, non-correlation is accepted. Over the period 1994-2019, the calculation of the Durbin-Watson statistic gives: $\mathrm{DW}=0.6032$. The reading on the Durbin-Watson table at the $5 \%$ threshold for $\mathrm{n}=26$ and $\mathrm{k}^{\prime}=2$ gives: $\mathrm{d}_{\mathrm{L}}=1.224$ and $\mathrm{d}_{\mathrm{U}}=1.553$. We observe, then, that $\mathrm{DW}<\mathrm{d}_{\mathrm{L}}$. Model errors with a quadratic trend are positively correlated. It is therefore necessary, under these conditions, that the autocorrelation be corrected. 
Appendix 6. Normality test of the residuals of the model with a quadratic trend (1980-1993)

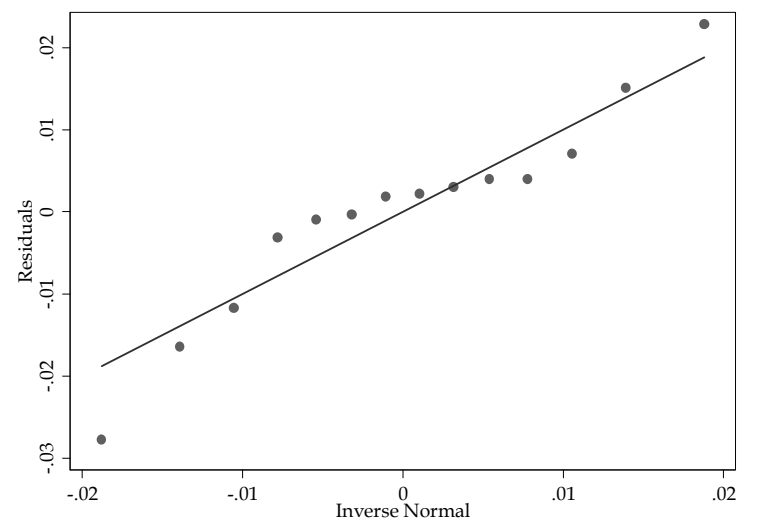

Appendix 7. Normality test of model residuals with a quadratic trend (1994-2019)

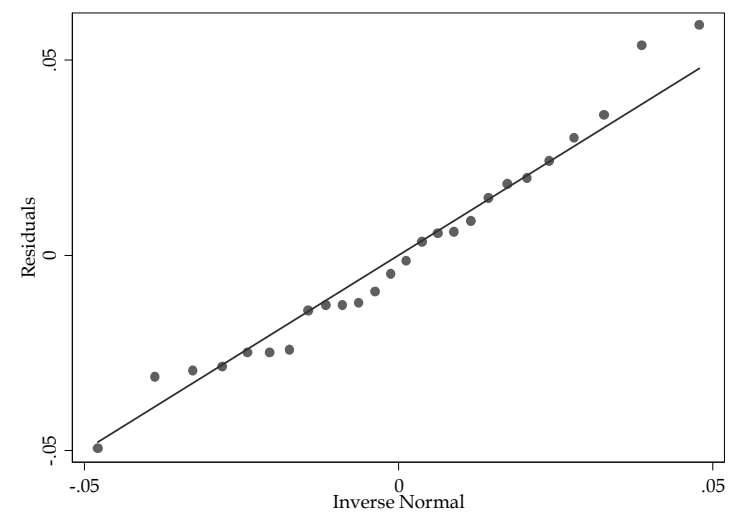

Appendix 8. Results of the validity tests of the model with a kinked trend estimated by the Ordinary Least Squares method

The normality test performed on the residuals of the model with a kinked trend estimated over the period 1980-2019 gives a probability of 0.00014. At the 5\% threshold, the null hypothesis of normality of the residuals of the model with a kinked trend is therefore rejected over the period in question. In this case, the other validity tests (Breusch-Pagan/Cook-Weisberg test and Durbin-Watson test) will not be performed, since they assume that the error terms follow a normal distribution.

Appendix 9. Normality test of the standard deviation of the logarithm of GDP per capita of WAEMU member states (1980-1993)

The probability of the normality test performed on the standard deviation of the logarithm of GDP per capita (in PPP dollars) of WAEMU member states over the period 1980-1993 is 0.18111 , so the null hypothesis of normality cannot be rejected at the $5 \%$ level. This result is further confirmed by the following Figure :

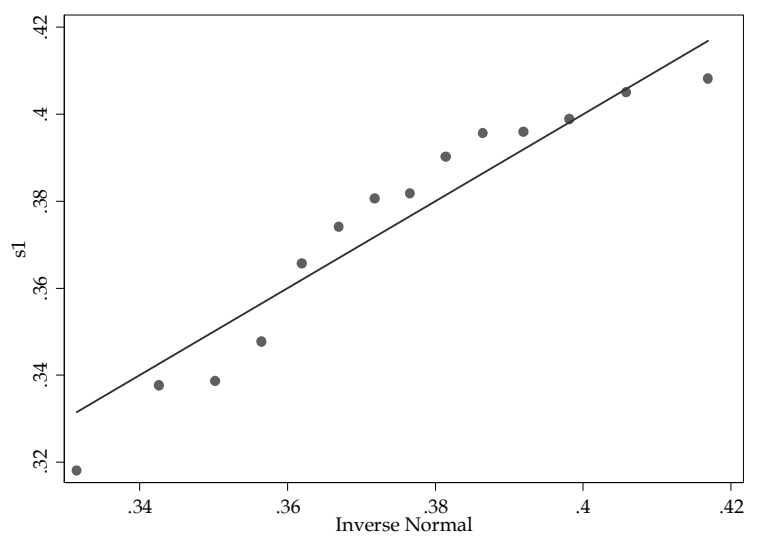


Appendix 10. Normality test of the standard deviation of the logarithm of GDP per capita of WAEMU member states (1994-2019)

The probability of the normality test applied to the standard deviation of the logarithm of GDP per capita (in PPP dollars) of WAEMU member states over the period 1994-2019 is 0.00279, so the null hypothesis of normality is rejected at the 5\% level. To remedy this situation and thus make the Student test applicable, the distribution of the sample was made compatible with the normal distribution by performing the Box-Cox transformation.

\section{Appendix 11. Fisher test (results)}

The probability of the Fisher test is 0.4818 , so the null hypothesis of equal variances cannot be rejected at the $5 \%$ level.

\section{Appendix 12. Figures showing the evolution of annual growth rates of WAEMU economies and their} Human Development Indices (HDI)
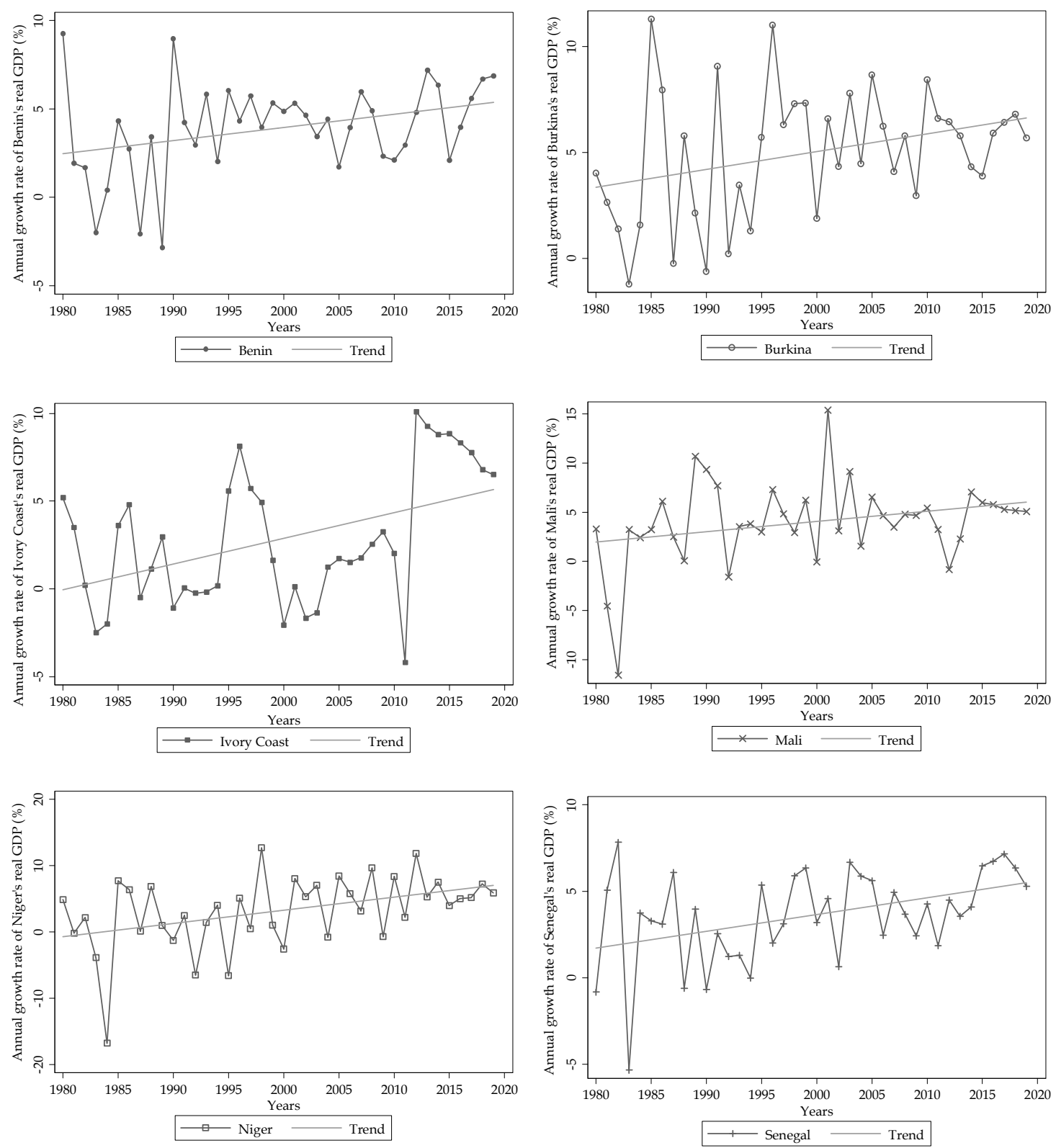

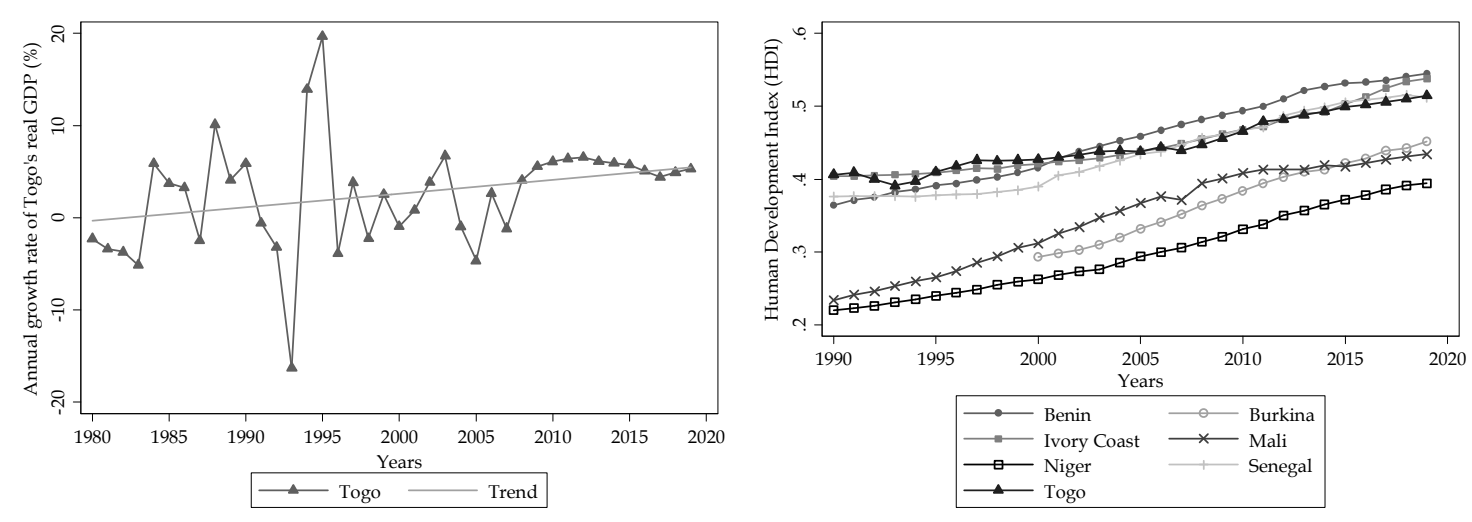

\section{Copyrights}

Copyright for this article is retained by the author(s), with first publication rights granted to the journal.

This is an open-access article distributed under the terms and conditions of the Creative Commons Attribution license (http://creativecommons.org/licenses/by/4.0/). 